\title{
Recognizing and modeling variable drawdown due to evapotranspiration in a semiarid riparian zone considering local differences in vegetation and distance from a river source
}

\author{
Brady Johnson, ${ }^{1}$ Bwalya Malama, ${ }^{2,3}$ Warren Barrash, ${ }^{1}$ and Alejandro N. Flores ${ }^{1}$ \\ Received 30 January 2012; revised 16 January 2013; accepted 30 January 2013; published 25 February 2013.
}

[1] Riparian zones in semiarid regions often exhibit high rates of evapotranspiration (ET) in spite of low-soil moisture content due to the presence of phreatophytic vegetation that is able to withdraw water from shallow aquifers. This work seeks to better define the relationship between ET, the saturated zone and the river boundary by comparing observed water table drawdown records to analytically modeled drawdown in fully penetrating wells of an unconfined aquifer in response to daily ET flux. ET at the Boise Hydrogeophysical Research Site (BHRS), a riparian zone in a temperate, semiarid environment, is calculated using a radiation-based method to provide ET values at four different wells with different vegetation densities. Analytically modeled drawdown response to ET forcing shows that drawdown magnitude increases with increasing distance from the river edge even as the surficial ET forcing remains constant. This behavior is also observed in well hydrographs and shows the buffering effect that flow from the river has on drawdown in fully penetrating riparian wells in highly permeable, unconfined aquifers. Relative contributions of river water to aquifer storage are calculated for ET-induced diurnal fluctuations of the water table at increasing distances from the river boundary. Failure to account for these spatial differences in drawdown related to the river source may explain some errors associated with estimating ET from well hydrographs alone.

Citation: Johnson, B., B. Malama, W. Barrash, and A. N. Flores (2013), Recognizing and modeling variable drawdown due to evapotranspiration in a semiarid riparian zone considering local differences in vegetation and distance from a river source, Water Resour. Res., 49, doi:10.1002/wrcr.20122.

\section{Introduction}

[2] Riparian areas are key to understanding regional water and energy balances, particularly in semiarid regions. However, seasonal evapotranspiration (ET) in riparian areas typically have high levels of uncertainty which limit our ability to accurately estimate the groundwater portion of water budgets [Goodrich et al., 2000]. Riparian zones in semiarid regions often exhibit high rates of ET in spite of low-soil moisture content due to vegetation that is able to withdraw water from permanent or seasonal ground water sources. Phreatophytes, such as cottonwoods (Populus spp.) and willows (Salix spp.), in temperate, semiarid zones, are deeprooted vegetation that fulfill a significant amount of their

\footnotetext{
${ }^{1}$ Department of Geosciences, Boise State University, Boise, Idaho, USA.

${ }^{2}$ Department of Geosciences, Montana Tech of the University of Montana, Butte, Montana, USA.

${ }^{3}$ Also at Sandia National Laboratories, Carlsbad Programs Group, Carlsbad, New Mexico, USA.

Corresponding author: W. Barrash, Department of Geosciences, Boise State University, 1910 University Dr., Boise, ID 83725, USA. (wbarrash@) cgiss.boisestate.edu)

C2013. American Geophysical Union. All Rights Reserved. 0043-1397/13/10.1002/wrcr.20122
}

transpiration needs directly from the saturated zone. Since these plants are in direct contact with the saturated zone, daily changes in water table levels can be seen as a direct response to vegetation transpiration (assuming other influences are negligible or otherwise accounted for). Transpiration generally follows the diurnal solar radiation cycle causing the water table to decline throughout the day as the plants move water from the saturated zone out through the leaves. During the night, transpiration becomes negligible and the water table recovers due to net inflow from the farfield [Loheide et al., 2005] to replace water lost through ET.

[3] White [1932] presented a simple model to estimate ET from diurnal fluctuations of the water table. The method calculates the groundwater component of evapotranspiration $\left(\mathrm{ET}_{g}\right)$ from the empirical relationship $E T_{g}=S_{y} \delta S+R$, where $S_{y}[-]$ is the specific yield, $\delta S[\mathrm{~L} / \mathrm{T}]$ is the net change in water table position for 1 period (1 day), and $R[L / T]$ is the net recovery rate of the ground water. $R$ can be calculated over a time of day (commonly 00:00-04:00 AM) when ET is assumed to be negligible with $R$ equal to change in head $[L]$ over change in time $[T]$. Studies have suggested improvements for the White method pertaining to the specific yield parameter [Meyboom, 1967; Loheide et al., 2005] and the recovery rate [Troxel, 1936; Loheide, 2008], but the method remains popular for calculating ET from well hydrographs. 
[4] Loheide et al. [2005] found that the method of White [1932] tends to overestimate ET and they presented new guidelines for its use including a more thorough method for estimating the readily available specific yield $\left(S_{y}^{*}\right)$ for subdaily testing. Gribovszki et al. [2008] applied the Dupuit approximation for saturated flow to more accurately relate the recovery rate $(R)$ to water level fluctuations and show that, for riparian zones dominated by phreatophytes, hydraulic head changes in response to transpiration can occur through the full saturated zone thickness. Much of the literature using the White [1932] method focuses on ways to better estimate hydraulic parameters (specific yield, primarily) but these efforts could benefit from better understanding of the role of the riparian system on daily drawdown observed in wells. Malama and Johnson [2010] presented an analytical model for well drawdown in response to ET which shows that drawdown magnitude will increase away from the river (even within a narrowly defined riparian corridor) in response to a spatially invariant surficial ET flux. This is due to decreasing river water contributions to ET flux with distance from the river. Failure to consider the distance of the observation well from the river can result in significant error in ET calculations from well hydrographs.

[5] Using this analytical solution, Malama and Johnson [2010] modeled drawdown at a range of distances from the river edge $(x)$ under spatially invariant ET rates. Results from this modeling show the buffering effect the river has on drawdown in an observation well. Solving for drawdown as $x \rightarrow \infty$ provides a maximum drawdown for a specified ET flux and allows for a quantitative calculation of the water contributions from aquifer storage and from the river system in diurnal fluctuations of the ground water table due to ET.

[6] In this paper, we use the model of Malama and Johnson [2010] with field data collected at a research well field adjacent to a controlled river in a temperate, semiarid riparian zone to (a) explain local variation in ET-induced drawdown between wells and (b) estimate the proportion of water contributed to transpiration from river leakage versus aquifer storage at different wells at different distances from the river. In this analysis, we account for local variation in ET rates due to vegetation density and compare the modeled results to observed hydrographs which show that changes in drawdown with distance from a river are recognizable, significant, and can be modeled to improve management and modeling of riparian zones.

\section{Theory}

[7] The analytical model developed in Malama and Johnson [2010] is a solution to hydraulic head changes in an unconfined aquifer in response to ET at the water table. The focus here will be on the semi-infinite flow domain (Figure 1) with a fixed head in a fully penetrating river serving as a lateral boundary condition and a fixed head boundary at $x=\infty$ in the far field away from the river equal to the river head. It should be noted that the model of Malama and Johnson [2010] allows for a temporally varying head boundary condition at the river. Two-dimensional flow is considered in an aquifer with a finite vertical extent $(z=b[L])$ and semi-infinite lateral extent $(x=0$ at riverland interface). The ET flux is applied uniformly at the

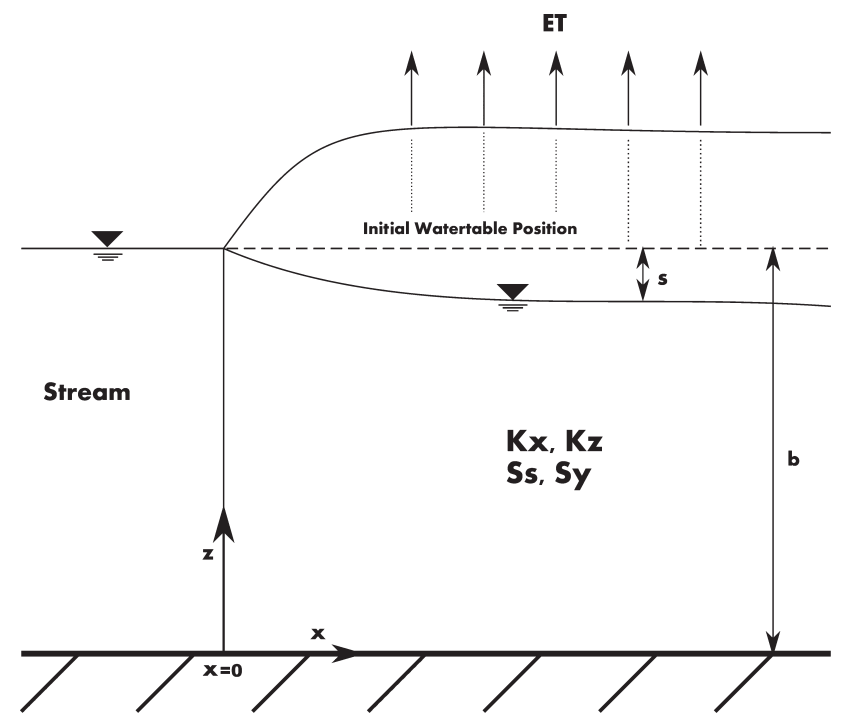

Figure 1. Conceptual model of the semi-infinite flow domain of the Malama and Johnson [2010] model. ET flux is applied as a forcing function at the water table uniformly over an area $\mathrm{x}$ distance from the river (with a known head elevation). Drawdown is calculated over the aquifer thickness (b) at point $x$.

water table. Drawdown $(s[L])$ from the initial steady state is governed by

$$
\frac{1}{\alpha_{z}} \frac{\partial s}{\partial t}=\frac{K_{x}}{K_{z}} \frac{\partial^{2} s}{\partial x^{2}}+\frac{\partial^{2} s}{\partial z^{2}}, \psi
$$

where $\alpha_{z}=\frac{K_{z}}{S_{s}}$ (vertical hydraulic diffusivity $\left.\left[L^{2} / T\right]\right), K_{x}$ and $K_{z}[L / T]$ are horizontal and vertical hydraulic conductivity, and $S_{s}\left[L^{-1}\right]$ is specific storage. Equation (1) is solved with the initial condition

$$
s(x, z, t=0)=0, \psi \quad \leftarrow \leftarrow
$$

and boundary conditions with no leakage at the bottom boundary $(z=0)$

$$
\left.\frac{\partial s}{\partial z}\right|_{z=0}=0, \psi
$$

and the ET function at the water table $(z=b)$

$$
-\left.K_{z} \frac{\partial s}{\partial z}\right|_{z=b}=\left.S_{y} \frac{\partial s}{\partial t}\right|_{z=b}-f(t), \psi
$$

where $f(t)$ is the ET flux function (presented in equation $(10))$. Drawdown at the river boundary $(x=0)$ and farfield $(x=\infty)$ are zero due to the constant head assumptions $(z=b)$.

[8] The solution to equations (1)-(4) obtained by Malama and Johnson [2010] shows that drawdown magnitude increases as the position of the well increases from the river boundary (increasing $x$, converging to a maximum drawdown curve beyond some large distance outside the range of influence of the river). Water contributions solely from the aquifer can be found by solving for drawdown as 
$x \rightarrow \infty$ where drawdown (s) is at a maximum and there is no river influence. Any drawdown value less than the maximum can be seen as having some river influence. The relative contributions between the river and aquifer can be found by calculating the ratio between maximum drawdown and the river-influenced drawdown.

\section{Boise Hydrogeophysical Research Site}

[9] The theory of Malama and Johnson [2010] can be applied at the Boise Hydrogeophysical Research Site (BHRS) which is a research well field and hydrologic processes observatory located at a riparian area in a temperate semiarid region about $15 \mathrm{~km}$ southeast of downtown Boise, ID adjacent to the Boise River (Figure 2). The unconfined aquifer consists of unconsolidated cobble, gravel, and sand fluvial deposits approximately $18 \mathrm{~m}$ thick and is underlain by a continuous clay layer [Barrash and Clemo, 2002; Barrash and Reboulet, 2004]. The 18 wells at the site are fully screened and fully penetrate the aquifer. Aquifer parameters have been estimated by hydrologic (pumping and slug tests) and geophysical techniques, and an overview of mean values based on fully penetrating pumping tests are presented in Table 1 [Barrash et al., 2006; Fox, 2006; Cardiff et al., 2009; Malama, 2011].

[10] The Boise River flows year round with discharge controlled by releases from Lucky Peak Dam and by releases and diversions from Diversion Dam (operated by U.S. Department of the Interior, Bureau of Reclamation), the latter of which is located about $600 \mathrm{~m}$ upstream from the BHRS. Spring runoffs can be high, fed from snowmelt in the upper reaches of the Boise River drainage. At such

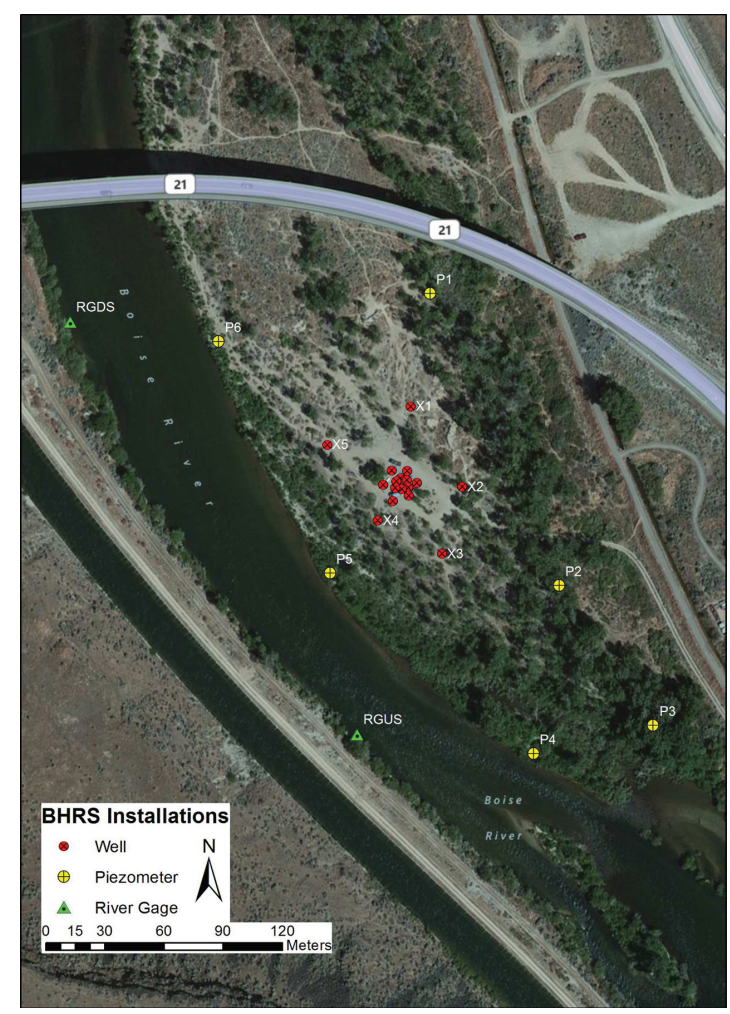

Figure 2. Aerial photograph of the Boise Hydrogeophysical Research Site with monitoring installations.
Table 1. Mean Aquifer Parameters Resulting from Analytical Modeling of Pumping Tests (73 Pumping Well-Observation Well Pairs) at the BHRS [Fox, 2006 $]^{\mathrm{a}}$

\begin{tabular}{clllc}
\hline Parameter & Mean & Maximum & Minimum & Units \\
\hline$K_{x}$ & $7.59 \times 10^{-4}$ & $1.29 \times 10^{-3}$ & $5.13 \times 10^{-4}$ & $\mathrm{~m} / \mathrm{s}$ \\
$K_{z}$ & $6.61 \times 10^{-4}$ & $1.29 \times 10^{-3}$ & $3.80 \times 10^{-5}$ & $\mathrm{~m} / \mathrm{s}$ \\
$S_{s}$ & $4.07 \times 10^{-5}$ & $1.29 \times 10^{-4}$ & $3.31 \times 10^{-5}$ & $\mathrm{~m}^{-1}$ \\
$S_{y}^{* \mathrm{a}}$ & 0.036 & 0.070 & 0.013 & {$[\mathrm{dim}]$} \\
\hline
\end{tabular}

${ }^{\mathrm{a}} S_{y}^{*}$ values are recognized to be lower than may be expected for unconsolidated coarse fluvial aquifers although similar values have been obtained from aquifer tests of relatively short duration [Neuman, 1972; Nwankwor et al., 1984, 1992; Moench, 1997; Barrash et al., 2006].

times, discharge in the lower Boise River (adjacent to the BHRS) can be relatively high and variable due to periodic releases from the dams. The summer months exhibit generally steady flow while water is fed to irrigation canals, and river flow decreases in the fall and winter months when the irrigation canals are no longer in use and flows are restricted to increase storage behind dams. All data concerning discharge in the Boise River are made available by the Bureau of Reclamation and daily averages of discharge and diversions for a 5 month period in 2009 are seen in Figure 3.

[11] Vegetation in the riparian zone at the BHRS is dominated by cottonwoods (Populus spp.) and coyote willow (Salix exigua) which are both known phreatophytes. In the western U.S., previous riparian ET studies in cottonwood dominated stands (both natural and restoration plots) have reported daily ET flux between 3.1 and $12 \mathrm{~mm}$ /day [Nagler et al., 2007; Pataki et al., 2005; Schaeffer et al., 2000]. Previous work at the BHRS has noted (a) root growth into some of the wells, which has been dense in the uppermost portion of several wells, and (b) diurnal fluctuations of the water table [Barrash et al., 2002; Cardiff et al., 2009; Malama and Johnson, 2010]. Phreatophytic vegetation obtains a significant amount of water from shallow

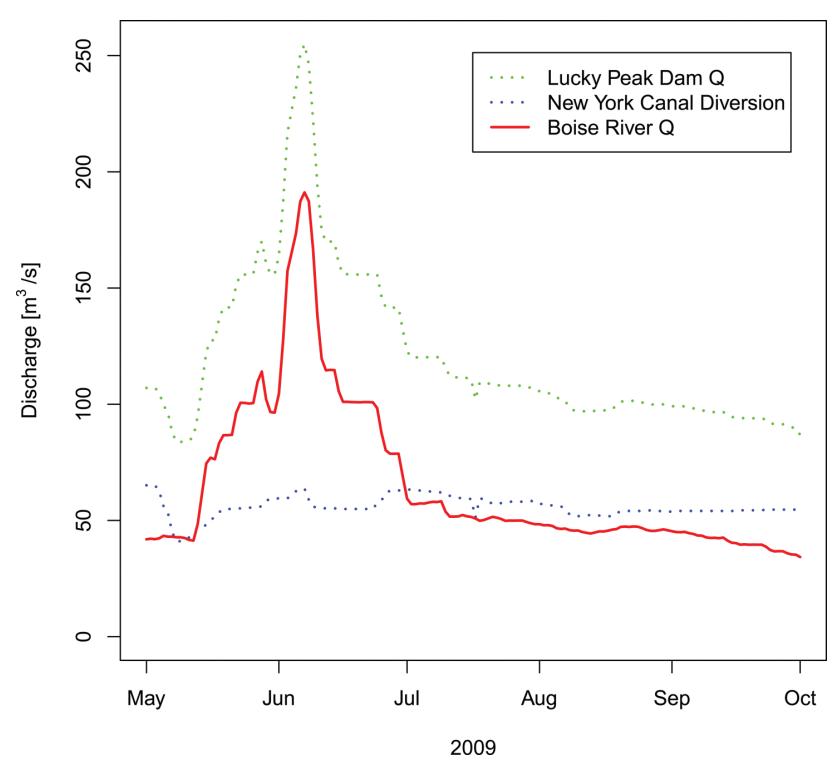

Figure 3. Daily average Boise River discharge from Lucky Peak Dam discharge and New York Canal diversions (all in cubic meters per second) from 1 May to 1 October 2009. 


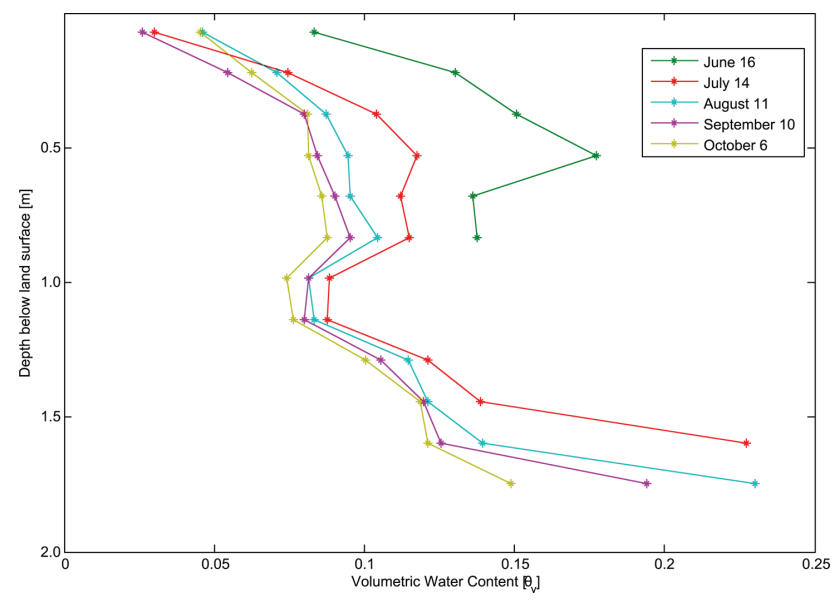

Figure 4. Neutron-probe soil moisture data collected near well X2 at the BHRS in 2010 showing the decrease in soil moisture over the summer and into the fall. Soil moisture shows little change at specific depths over time due to low precipitation rates and high potential evaporation. Note that two rain events $(3.8 \mathrm{~cm}$ on 6-7 August and $1.9 \mathrm{~cm}$ on 4-5 October) occurred shortly before measurements on August 11 and October 6 without reversing the drying trend or shifting the profiles to significantly higher moisture contents. The depth of data obtained at the time of measurement is dependent on the elevation of the water table (i.e., thickness of the unsaturated zone).

aquifers and the capillary fringe and is common in riparian zones, particularly in semiarid regions. Access to the saturated zone allows these plants to thrive in areas where unsaturated soil moisture is near residual amounts through much of the year (e.g., Figure 4). For this study, we examine ET and associated water level changes at four wells at the BHRS which have different vegetation densities (Figure 5) and are at different distances from the Boise River (Table 2).

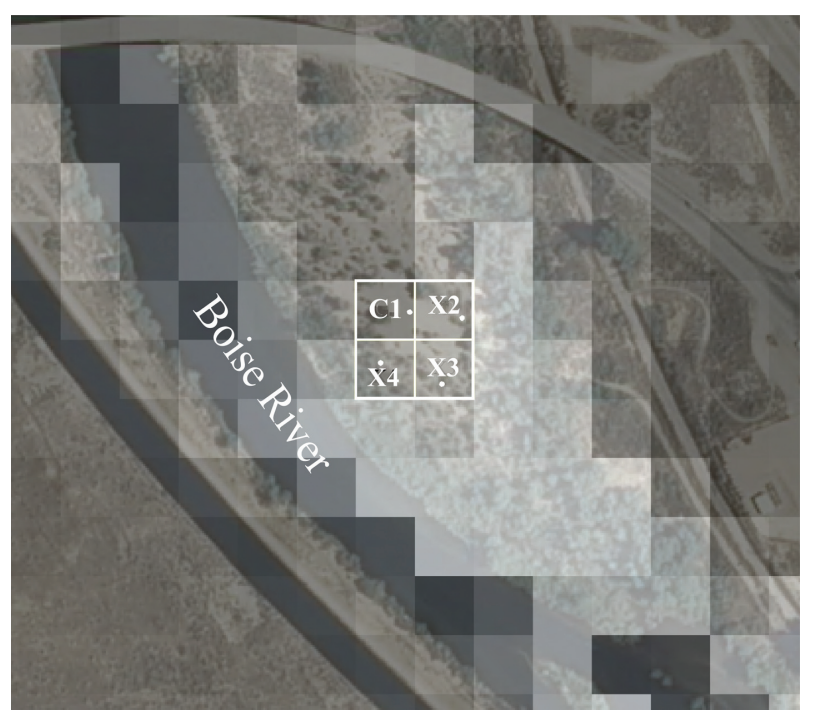

Figure 5. Aerial view over the BHRS and the four wells for which ET was calculated showing Landsat pixels. Pixels for which unique vegetation densities (NDVI) were recorded are outlined in white.
Table 2. Measured Distance From Wells to the River, 3 July 2009

\begin{tabular}{lc}
\hline Well & Distance to River [m] \\
\hline X2 & 82.23 \\
C1 & 61.23 \\
X3 & 52.55 \\
X4 & 35.76 \\
\hline
\end{tabular}

Water level changes are recorded by in-well pressure transducers at 15 min intervals. Data presented here were collected using a vented InSitu miniTroll or sealed Solinst Levelogger Junior (barometric compensation for Solinst Levelogger was completed with data collected from a Solinst Barologger).

\section{Diurnal Fluctuations in Response to ET}

[12] Figure 6 shows the depth to water below land surface for several daily cycles at the BHRS where plants are drawing water from the saturated zone during the day and where the aquifer is recovering at night. Recovery rate and change in storage ( $R$ and $\delta S$, respectively) calculated using the method of White [1932] are labeled in the figure. The recovery rate calculated here is a linear approximation of recovery rate starting when ET is assumed to be negligible (Figure 6). Loheide et al. [2005] found this assumption to be reasonable when a value of readily available specific yield could be determined. Readily available specific yield (often noted as $S_{y}^{*}$ ) is lower than traditionally defined specific yield and is used to describe water used during a short period of time, typically less than $12 \mathrm{~h}$ [Meyboom, 1967; Loheide et al., 2005; Barrash et al., 2006]. Troxel [1936] first noted that the recovery rate is nonlinear, and the curvature seen nearing peak recovery in well hydrographs (Figure 6) shows that the rate is not constant in time. Timedependent recovery rate is formulated by Loheide [2008] but the original method of White [1932] is limited by the assumption of constant recovery rate.

[13] ET calculated after White [1932] is a measure of groundwater contributions (thus, it is often written as $\mathrm{ET}_{g}$ ) as the aquifer is assumed to be coarse in grain size and shallow where vegetation can access the groundwater, and it is assumed that the unsaturated zone does not contribute significant amounts of water to ET. Although wells in White [1932] are located in the riparian zone, there is no mention of the distance away from the river each well is located. This, as shown in the analytical solution of Malama and Johnson [2010] to drawdown, can be problematic as drawdown magnitude is a function of lateral distance from the river boundary due to leakage from the river contributing to ET flux [Malama and Johnson, 2010].

\section{Evapotranspiration}

[14] With the many factors that need to be considered when estimating ET, collection of data via remote sensing techniques, particularly by orbiting satellite, is often preferred because it reduces the amount of ground data that need to be collected. We use this approach here but also note that radiation data collected from remotely sensed 


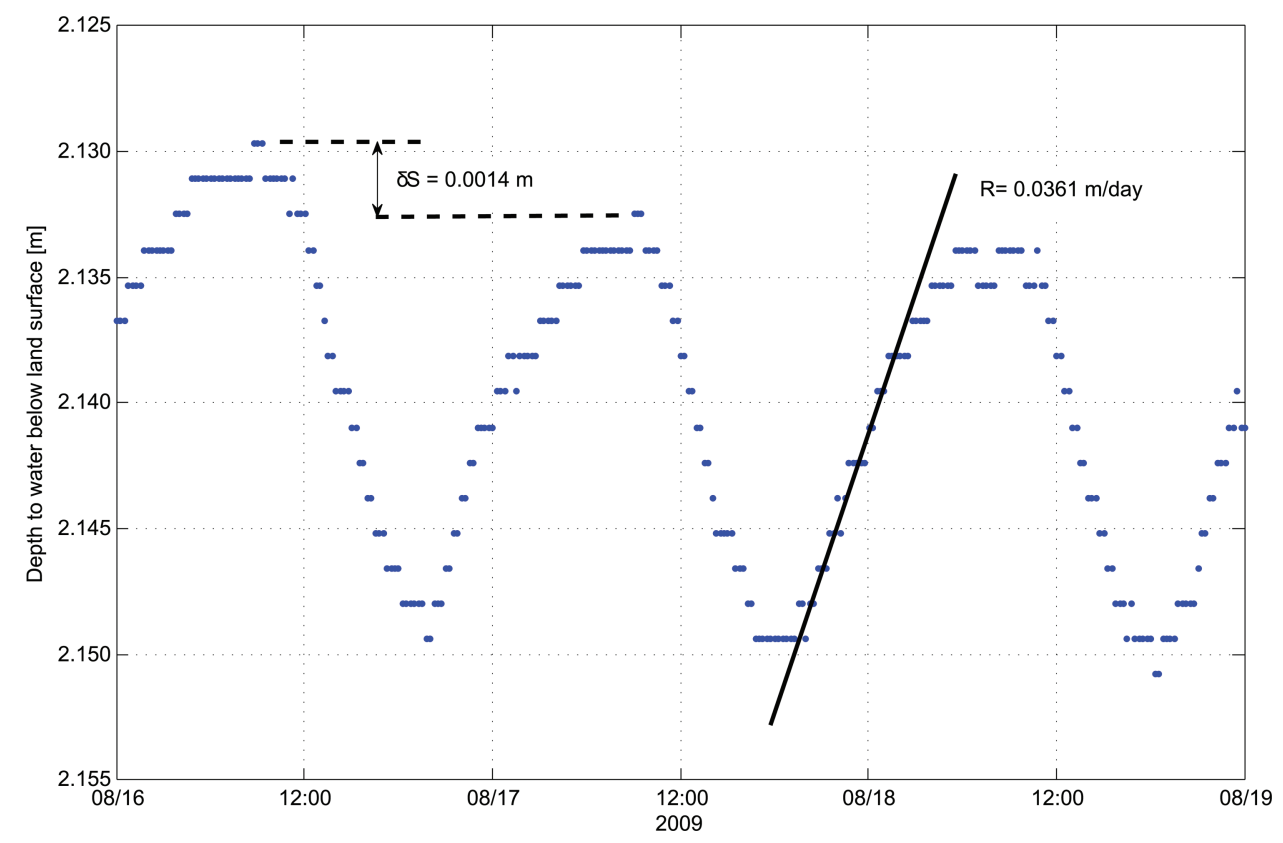

Figure 6. Change in depth to water with time in well $\mathrm{X} 2$ at the BHRS. $\delta S$ is the net change in water table position for 1 period (1 day) and $R[L / T]$ is the net recovery rate of the ground water.

data were checked and found to compare well with local ground-based instrument measurements [Johnson, 2011]. ET mass flux $\left(\mathrm{ET}_{m f}\left[\mathrm{~kg} \mathrm{~m}^{-2} \mathrm{~s}^{-1}\right]\right)$ can be estimated using a derivation of the Priestley-Taylor equation [Jiang and Islam, 2001]:

$$
\lambda \mathrm{ET}_{m f}=\phi\left(\frac{\Delta}{\Delta+\gamma}\right)\left(R_{n}-G\right), \psi
$$

which has the advantage of containing variables that can be derived from remote sensing data along with common meteorological data. These parameters include soil heat flux $\left(G\left[\mathrm{Wm}^{-2}\right]\right)$, net radiation $\left(R_{n}\left[\mathrm{Wm}^{-2}\right]\right)$, and an empirical parameter $(\varphi)$ that is the actual evaporation rate divided by the equilibrium evaporation rate (here, 1.26). Lambda $\left(\lambda\left[\mathrm{Jkg}^{-1}\right]\right)$ is the latent heat of vaporization, and the slope of the saturated vapor pressure curve $(\Delta)$ and the psychrometric constant $(\gamma \psi[\mathrm{kPa} / \mathrm{K}])$ are functions of air temperature. $G$ and $R_{n}$ are related by Moran et al. [1989, 1994] and Batra et al. [2006]:

$$
G=0.583 \exp (-2.13 \mathrm{NDVI}) R_{n}, \psi
$$

where NDVI quantifies living vegetation through the normalized difference in reflectance values between the nearinfrared and red wavelengths from Landsat 5 TM data (bands 4 and 3, respectively) [Moran et al., 1989; Liang, 2004; ENVI, 2006] as:

$$
\text { NDVI }=\frac{\text { Band } 4-\text { Band } 3}{\text { Band } 4+\text { Band } 3} \cdot \psi
$$

[15] $R_{n}$ is modeled after Bisht et al. [2005] as a function of time:

$$
R_{n}(t)=R_{n, \max } \sin (\omega t) \cdot \psi
$$

[16] The Priestley-Taylor equation (5) equates daily ET amplitude to:

$$
Q=\frac{R_{n, \max } \phi \Delta}{\rho \lambda(\Delta+\gamma)}[1-0.583 \exp (-2.13 \mathrm{NDVI})], \psi
$$

where $Q$ is the amplitude of ET flux at the water table due to ET and $R_{n, \max }$ is the maximum net radiation measured during the day [Batra et al., 2006; Bisht et al., 2005]. The daily ET function then becomes a smooth sine curve described by:

$$
f(t)=\underset{\rho \psi}{\stackrel{\mathrm{ET}}{\rho \psi}}=\left\{\begin{array}{cc}
Q \sin (\omega t) & \left.\forall t \in \leftarrow 0, t_{\text {day }}\right] \\
0 & \forall t>\psi_{\text {day }}
\end{array},\right.
$$

where $\rho \psi$ is the density of water and $\omega=\pi / t_{\text {day }}$ where $t_{\text {day }}=t_{\text {set }}-t_{\text {rise }}$ with $t_{\text {set }}$ and $t_{\text {rise }}$ the times where net radiation becomes negative and positive, respectively. Figure $7 \mathrm{a}$ shows this function over a $24 \mathrm{~h}$ period where $t_{\text {day }}$ is the time from sunrise to sunset $(12 \mathrm{~h}$, here) and $Q=16 \mathrm{~mm} /$ day.

[17] The ET function is applied at the water table with the modeled head presented in the analytical solution [Malama and Johnson, 2010] being the drawdown in the well open to the full aquifer saturated thickness. Figure 7 shows (a) the ET forcing for a single day and (b) the modeled drawdown response in the well. Here $t=0$ corresponds to the time when net radiation becomes positive. Note that peak drawdown occurs after the peak ET flux because drawdown continues as long as the ET rate is greater than the aquifer recharge rate.

[18] Following the work of Shah et al. [2007], water contribution from the unsaturated zone is neglected and all available water for ET is assumed to be from the saturated zone. This is also supported in general by White [1932] who 


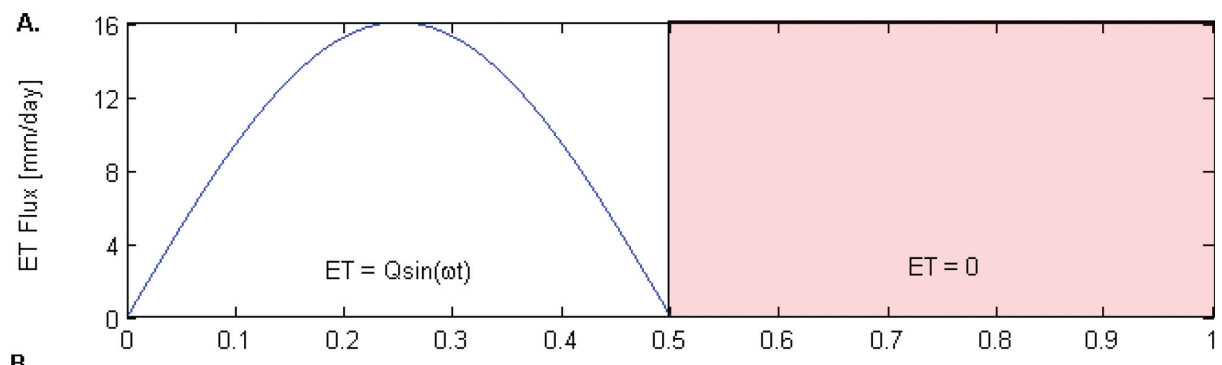

B.

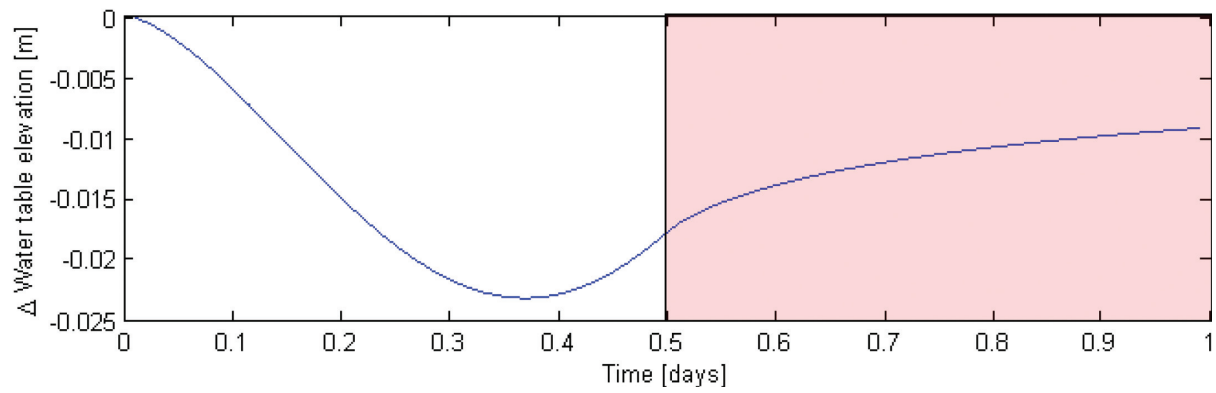

Figure 7. (A) Modeled ET signal with amplitude $(Q)$ of $16 \mathrm{~mm} /$ day and a length of $12 \mathrm{~h}\left(t_{\text {day }}=0.5\right)$ and (B) the resulting simulated drawdown response at a well $60 \mathrm{~m}$ from the river boundary. Note the incomplete recovery of the water table due to water lost to ET.

found that, in riparian zones dominated by phreatophytes, ground water is the dominant source of water lost to the atmosphere (note: this methodology could underestimate ET if used in areas where water from the unsaturated zone is a significant source for riparian vegetation). This is also supported by site observations at the BHRS based on measured soil moisture (see section 4, above and Figure 4).

\subsection{Daily Drawdown Versus ET Magnitude Across the BHRS}

[19] The diurnal signal of drawdown varies in magnitude in response to ET but is also controlled by the distance of a given well from the river. For comparison, daily drawdown magnitude is quantified as the maximum change in water level at a well during a day. This is not synonymous with the storage term in White [1932] but is an instantaneous measure of maximum drawdown experienced for any one day. Well hydrographs at the BHRS during periods of ET forcing typically show high daily water levels during the early morning hours $(2: 00-7: 00)$ followed by drawdown during the hours when radiation is positive resulting in maximum drawdown around 19:30, followed by a steep recovery overnight. Water levels typically do not return to the same level as the previous day. This difference in amount of water $(\delta S$, Figure 6) is the residual drawdown between two maxima and is the storage term from White [1932]; this effect is predicted by the model of Malama and Johnson [2010].

[20] At a given distance $(x)$ from the river, well drawdown magnitude should be strongly correlated with ET magnitude which incorporates vegetation density variation through NDVI (equation (7)). The wells monitored at the BHRS are at different distances from the river edge (Figure 5 and Table 2) and these differences are apparent in the well hydrographs. Figure 8 plots ET amplitude and daily drawdown in four wells at the BHRS over the summer of 2009 for periods of time that have satellite data to support
ET calculations as in equation (9). Data were further limited to periods where river stage had no significant changes over the presented period and $72 \mathrm{~h}$ prior.

[21] As shown in Figure 8a, X4 has the highest calculated ET amplitude for the majority of the year, followed by wells X3, X2, and C1, respectively. This order is seen in the calculated NDVI values at each well (Figure 9) and, following the assumption that radiation and temperature are the same at each well, vegetation should be the only difference in calculating ET. However, the daily drawdown magnitudes in Figure $8 \mathrm{~b}$ show a reversal from what is expected if distance to river were not considered. Well X4, which has the highest calculated ET values, is closest to the river and typically has the lowest drawdown magnitudes while well X2 is furthest from the river and has the highest drawdown values.

\subsection{Comparison of ET Calculation Methods at the BHRS}

[22] ET was calculated at the four example wells (Figure 5 and Table 2) at the BHRS after White [1932] from well hydrographs for a 5 day period in July 2009, and was compared with calculated values from the radiation-based model from Batra et al. [2006]. Wells X4 and X2 are closest and furthest, respectively, from the river boundary at the BHRS (Table 2) and the results for these two example wells are shown in Figure 10.

[23] The White [1932] method of calculating ET flux is based upon the analysis of hydrographs and does not account for radiation physics, a possible river recharge source, variations in distance from a river source, or differences in vegetation influence on ET flux between nearby wells. As the magnitude of the observed drawdown in a given well increases, the calculated ET flux from White's method increases as well. This method shows higher ET than the radiation-based method at well X4 for 4 of the 5 days shown in Figure 10a. However, ET from White [1932] 

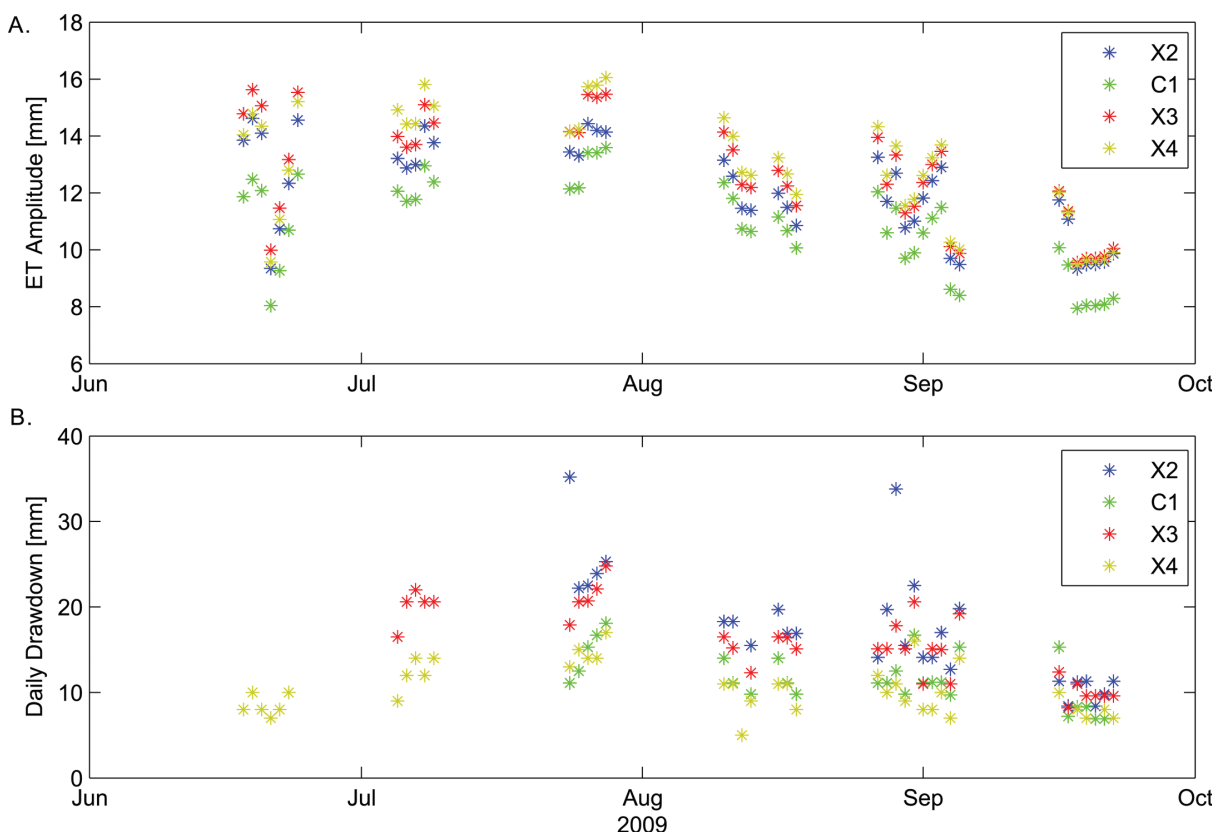

Figure 8. (A) ET amplitude and (B) well drawdown over the summer of 2009 for four wells at the BHRS. Although X4 usually has the highest calculated ET rates, daily drawdown is consistently lower than the other wells due to its proximity to the river (see Table 2).

at well X2 is significantly higher than radiation-based calculations for all 5 days, with values being $60 \%$ higher for 3 of the days presented in Figure 10b. Records from in-well pressure transducers show greater drawdown in well X2 than $\mathrm{X} 4$ despite higher calculated $\mathrm{ET}$ at well $\mathrm{X} 4$ via the radiation model.

\section{Modeling of River and Aquifer Storage Contributions to ET as a Function of Distance}

[24] The analytical solution to drawdown in response to ET forcing [Malama and Johnson, [2010] shows that drawdown magnitude increases with increasing distance from the river edge (Figure 11) for constant surficial ET forcing. Failure to account for distance from the river boundary

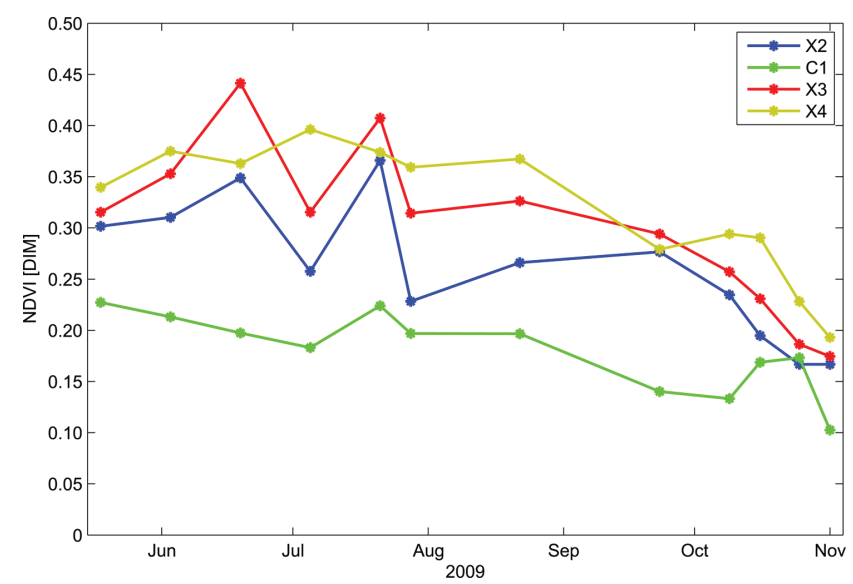

Figure 9. Calculated NDVI from Landsat $5 \mathrm{TM}$ data at each of the four observation wells throughout the study. Unique values correspond to pixels shown in Figure 5. may explain, in part, the overestimation of ET at well X2 using the White [1932] method to calculate ET. For the drawdown modeling in response to daily ET flux using the method of Malama and Johnson [2010], bulk aquifer parameters were used that were similar to results from previous fully penetrating pumping tests [Fox, 2006; Barrash et al., 2006] and optimization through observed drawdown records. These values are listed in Table 3.

[25] ET rates were calculated from the radiation-based methodology presented earlier. The area for which a rate is calculated is equal to the 30 meter pixel from Landsat data

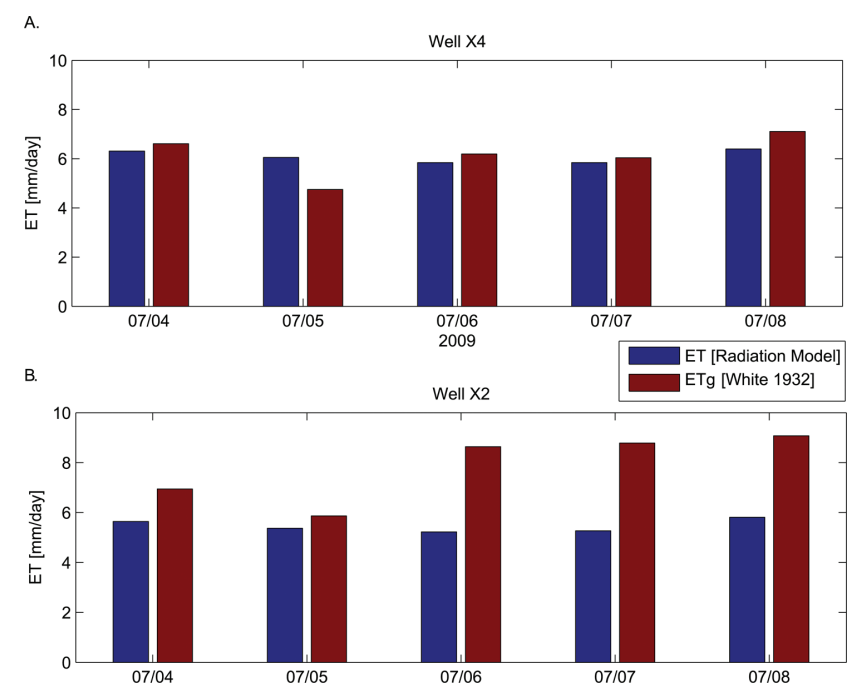

Figure 10. Results of ET calculated at (A) well X4 and (B) well X2 over 5 days using the radiation-based method from Batra et al. [2006] compared to $\mathrm{ET}_{g}$ calculated from well hydrographs [White, 1932]. 


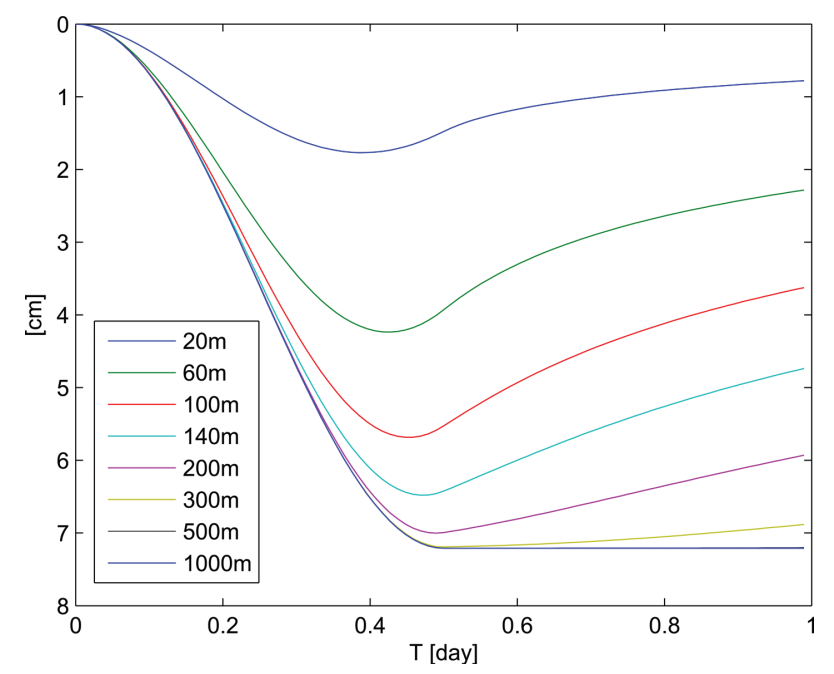

Figure 11. Modeled daily drawdown in a well as a function of time at different lateral distances from the river boundary.

that serves as the basis for vegetation quantification (Figure 5). For examination of the contributions between aquifer and river, the same ET rate (amplitude $(Q)=16 \mathrm{~mm} /$ day) was used to model drawdown at increasing distances from the river edge.

[26] Here the river boundary and infinity boundary are maintained at zero drawdown with the same initial head conditions for clarity in illustrating the relationships. The model of Malama and Johnson [2010] can be used to address the effects of ET with river leakage under timevarying river stage conditions. Drawdown curves were modeled at the river boundary and with increasing distance from the river. These curves were integrated over the ET period, $t_{\text {day }}$ in equation (10), to determine the drawdown due to ET forcing (Figure 7). We do this to minimize bias in the results due to incomplete recovery in water table elevation as is commonly observed in seasonal water table trends, particularly as the lateral distance increases beyond the influence of the river. The ratio of river contribution to ET flux was found by dividing this drawdown by the maximum drawdown (i.e., at sufficient distance from the river that the river does not affect daily drawdown). This drawdown ratio is subtracted from unity where a resulting value of 1.0 shows complete river input and 0.0 shows complete aquifer input to ET-induced drawdown.

[27] The relative contributions to ET flux from the river and aquifer are shown in Figure 12. The inset in Figure 12 shows the modeled relative contributions at each of the four wells where drawdown was monitored and ET was

Table 3. Bulk Aquifer Parameters Used for Drawdown Modeling at the BHRS

\begin{tabular}{ccc}
\hline Parameter & Value & Units \\
\hline$K_{x}$ & $6.4 \times 10^{-4}$ & $\mathrm{~m} / \mathrm{s}$ \\
$K_{z}$ & $2.5 \times 10^{-4}$ & $\mathrm{~m} / \mathrm{s}$ \\
$S_{s}$ & $1.0 \times 10^{-6}$ & $m^{-1}$ \\
$S_{y}$ & 0.05 & {$[\mathrm{dim}]$} \\
$b$ & 16 & $\mathrm{~m}$ \\
\hline
\end{tabular}

calculated at the BHRS using the model of Malama and Johnson [2010]. The relative contribution of river water decreases with increasing distance from the river boundary but is still a significant source at distances within $150 \mathrm{~m}$ of the river boundary (e.g., over $20 \%$ from the river source at well X2, $82.23 \mathrm{~m}$ from the river boundary).

\section{Discussion}

[28] The river boundary plays a vital role in the drawdown observed at a given well due to ET. ET-induced drawdown brings water into the aquifer rapidly and continually at the river boundary because of the (a) high conductivity of the aquifer, (b) river (constant head source, modeled here as fully penetrating), and (c) continuous presence of vegetation from the river edge to large lateral distances that maintain ET-induced drawdown during the daylight period. This river contribution progressively suppresses ET-induced drawdown in well hydrographs with decreasing distance from the river boundary. This effect is seen in the observed differences in drawdown magnitude at the BHRS (Figure 8) at wells that have similar vegetation types and densities (as determined through NDVI). It should be noted that the assumptions of a fully penetrating river and infinitely extensive riparian zone are not often satisfied in practice and will result in a modeled bias toward greater relative contributions from the river.

[29] In the model, significant river leakage contributions to the ET flux occur within $150 \mathrm{~m}$ from the river due to ETinduced drawdown in the laterally extensive riparian area which extends to infinity. For example, although net river water contributions decrease progressively with lateral distance from the river, more than $20 \%$ of the water drawn from the aquifer by ET at well X2 comes from the river (Figure 12). The aquifer serves primarily as a conduit and temporary store for the river water that is transmitted to the phreatophyte vegetation which transpire this water to the atmosphere. That is, there is inflow from the constant head lateral boundaries at the river and at infinity distance from the river. The analytical model [Malama and Johnson, 2010] is constrained laterally by a time-invariant lateral Dirichlet boundary condition at $x=\infty$ with head equal to a river-stage dependent Dirichlet boundary condition at the river. These conditions supply the water for recovery at night when there is no ET and on a seasonal basis after the leaves fall and before the growing season begins again.

\section{Conclusions}

[30] Analytical modeling of drawdown in response to ET forcing allows for analysis of the relative contribution of river water to aquifer storage water at increasing distances from a river boundary in a semiarid riparian zone. Observation wells closer to the river boundary display drawdown of a smaller magnitude than wells further from the river given the same surficial ET forcing due to higher relative contribution of river water. In unconfined, coarse sand and gravel aquifers such as the BHRS, the river can be a significant source for ET flux up to $150 \mathrm{~m}$ away from the boundary under the assumption of a fully penetrating river boundary.

[31] For these reasons, the distance from the river boundary should be considered in the analysis of diurnal 


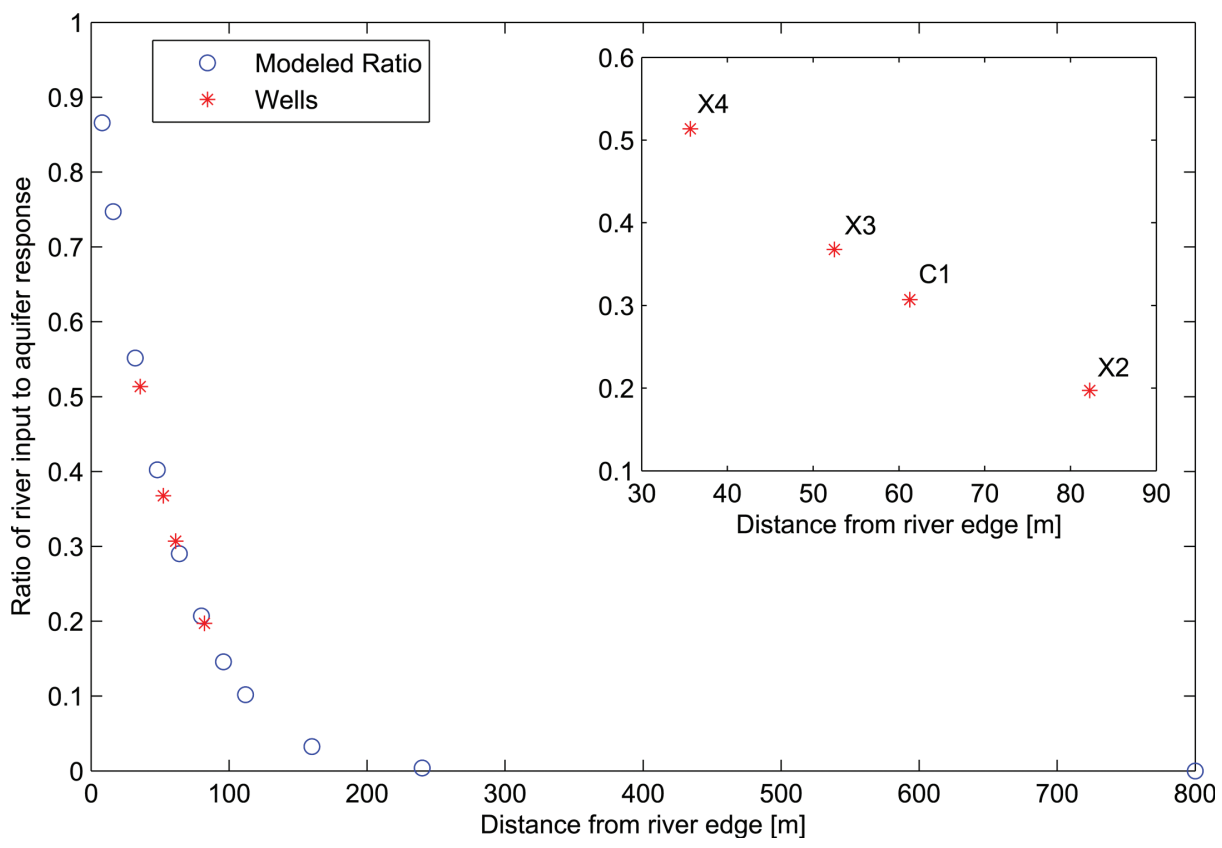

Figure 12. Modeled relative contribution of river as water source to ET as a function of lateral distance from river.

fluctuations of the water table in response to ET. That is, much of the variation in ET calculated from these hydrographs may be due to the spatial differences of the wells with respect to the river as opposed to actual differences in ET at the wells. Accounting for relative contributions between the river and aquifer may help to minimize errors associated with quantifying ET for water and energy budgets in the riparian zone. Future work to modify the analytical model [Malama and Johnson, 2010] for partial penetration of the river into the aquifer [e.g., Butler et al. 2001] would improve the accuracy of estimates of relative flux contributions from river leakage and aquifer storage.

[32] Acknowledgments. This research was supported by EPA grants X-96004601-0 and X-96004601-1, and by the U.S. RDECOM ARL Army Research Office under grant W911NF-09-1-0534.

\section{References}

Barrash, W., and T. Clemo (2002), Hierarchical geostatistics and multifacies systems: Boise Hydrogeophysical Research Site, Boise, Idaho, Water Resour. Res., 38(10), 1196, doi:10.1029/2002WR001436.

Barrash, W., T. Clemo, D. W. Hyndman, E. Reboulet, and E. Hausrath (2002), Tracer/time-lapse radar imaging test; Design, operation, and preliminary results: Report to EPA for Grant X-970085-01-0 and to the U.S. Army Research Office for Grant DAAH04-96-1-0318, Center for Geophysical Investigation of the Shallow Subsurface Tech. Rep. BSU CGISS 02-03, 120 p., Boise State Univ., Boise, ID.

Barrash, W., T. Clemo, J. J. Fox, and T. C. Johnson (2006), Field, laboratory, and modeling investigation of the skin effect at wells with slotted casing, J. Hydrol., 326(1-4), 181-198, doi:10.1016/j.jhydrol.2005. 10.029 .

Barrash, W., and E. Reboulet (2004), Significance of porosity for stratigraphy and textural composition in subsurface, coarse fluvial deposits: Boise Hydrogeophysical Research Site, Geol. Soc. Am. Bull., 116, 10591073, doi:10.1130/B25370.1.

Batra, N., S. Islam, V. Venturini, G. Bisht, and L. Jiang (2006), Estimation and comparison of evapotranspiration from MODIS and AVHRR sensors for clear sky days over the southern Great Plains, Remote Sens. Environ., $103,1-15$.
Bisht, G., V. Venturini, L. Jiang, and S. Islam (2005), Estimation of the net radiation using MODIS (moderate resolution imaging spectro-radiometer) data for clear sky days, Remote Sens. Environ., 97, 52-67.

Butler, J. J., V. A. Zlotnik, and M.-S. Tsou (2001), Drawdown and stream depletion produced by pumping in the vicinity of a partially penetrating stream, Ground Water, 39(5), 651-659.

Cardiff, M., W. Barrash, P. Kitanidis, B. Malama, A. Revil, S. Straface, and E. Rizzo (2009), A potential-based inversion of unconfined steady-state hydraulic tomography, Ground Water, 47(2), 259-270.

ENVI (2006), ENVI Reference Guide Version 4.3, July 2006 ed., ITT Visual Inf. Solutions, Boulder, Colo.

Fox, J. J. (2006), Analytical modeling of fully penetrating pumping tests at the Boise Hydrogeophysical Research Site for aquifer parameters and wellbore skin, M.S. thesis, 132 p., Boise State Univ., Boise, ID.

Goodrich, D. C., et al. (2000), Seasonal estimates of the riparian evapotranspiration using remote and in-situ measurements, Agric. For. Meteorol., 105, 281-309.

Gribovszki, Z., P. Kalicz, J. Szilágyi, and M. Kucsara (2008), Riparian zone evapotranspiration estimation from diurnal groundwater level fluctuations, J. Hydrol., 349, 6-17.

Jiang, L., and S. Islam (2001), Estimation of surface evaporation map over southern Great Plains using remote sensing data, Water Resour. Res., 37(2), 329-340.

Johnson, B. (2011), Evapotranspiration in the riparian zone of the lower Boise River with implications for groundwater flow, M.S. thesis, 74 p., Boise State Univ., Boise, ID.

Liang, S. (2004), Quantitative Remote Sensing of Land Surfaces, John Wiley, N. J.

Loheide, S. P. (2008), A method for estimating subdaily evapotranspiration of shallow groundwater using diurnal water table fluctuations, Ecohydrology, 1, 59-66.

Loheide, S. P., J. J. Butler Jr., and S. M. Gorelick (2005), Estimation of groundwater consumption by phreatophytes using diurnal watertable fluctuations: A saturated-unsaturated flow assessment, Water Resour. Res., 41, W07030, doi:10.1029/2005WR003942.

Malama, B. (2011), Alternative linearization of water table kinematic condition for unconfined aquifer pumping test modeling and its implications for specific yield estimates, J. Hydrol., 399(3-4), 141-147.

Malama, B., and B. Johnson (2010), Analytical modeling of saturated zone head response to evapotranspiration and river-stage fluctuations, $J$. Hydrol., 382, 1-9, doi:10.1016/j.jhydrol.2009.12.010.

Meyboom, P. (1967), Groundwater studies in the Assiniboine river drainage basin-part ii: Hydrologic characteristics of phreatophytic vegetation in south-central Saskatchewan, Bull. Geol. Surv. Canada, 139, 64 p. 


\section{JOHNSON ET AL.: MODELING DRAWDOWN DUE TO ET IN A SEMIARID RIPARIAN ZONE}

Moench, A. F. (1997), Flow to a well of finite diameter in a homogeneous, anisotropic water table aquifer, Water Resour. Res., 33(6), 1397-1407.

Moran, M. S., R. D. Jackson, L. H. Raymond, L. W. Gay, and P. N. Slater (1989), Mapping surface energy balance components by combining Landsat thematic mapper and ground-based meteorological data, Remote Sens. Environ., 30, 77-87.

Moran, M. S., W. P. Kustas, A. Vidal, D. I. Stannard, J. H. Blanford, and W. D. Nichols (1994), Use of ground-based remotely sensed data for surface energy balance evaluation of a semiarid rangeland, Water Resour. Res., 30(5), 1339-1349.

Nagler, P., et al. (2007), Evapotranspiration in a cottonwood (Populus fremontii) restoration plantation estimated by sap flow and remote sensing methods, Agric. For. Meteorol., 144, 95-110.

Neuman, S. P. (1972), Theory of flow in unconfined aquifers considering delayed response of the water table, Water Resour. Res., 8(4), 10311045 .

Nwankwor, G. I., J. A. Cherry, and R. W. Gillham (1984), A comparative study of specific yield determinations for a shallow sand aquifer, Ground Water, 22(6), 764-772.
Nwankwor, G. I., R. W. Gillham, G. van der Kamp, and F. F. Akindunni (1992), Unsaturated and saturated flow in response to pumping of an unconfined aquifer: Field evidence of delayed drainage, Ground Water, 30(5), 690-700

Pataki, D., S. Bush, and P. Gardner (2005), Ecohydrology in a Colorado River riparian forest: Implications for the decline of Populus fremontii, Ecol. Appl., 15, 1009-1018.

Schaeffer, S., D. Williams, and D. Goodrich (2000), Transpiration of cottonwood/willow forest estimated from sap flux, Agric. For. Meteorol., $105,257-270$.

Shah, N., M. Nachabe, and M. Ross (2007), Extinction depth and evapotranspiration from ground water under selected land covers, Ground Water, 45(3), 329-338.

Troxel, H. C. (1936), The diurnal fluctuation in the groundwater and flow of the Santa Ana River and its meaning, EOS Trans., 17(4), 496-504.

White, W. N. (1932), A method for estimating ground-water supplies based on discharge by plants and evaporation from soil-Results of investigations in the Escalante Valley, Utah, U.S. Geological Survey Water Supply Paper 659-A, 105 p. 